\title{
Late-onset clozapine-induced neutropenia treated with lithium
}

\author{
Pelin Tas Durmus ${ }^{1 \oplus}$, Yasemin Gorgulu $^{1 \oplus}$, Mehmet Bulent Sonmez $^{1 \oplus}$, Rugul Kose Cinar $^{1 \oplus}$ \\ ${ }^{1}$ Trakya University, Faculty of Medicine, Department of Psychiatry, Edirne - Turkey
}

\begin{abstract}
Clozapine is a second-generation antipsychotic drug, proven to be effective in treatment-resistant schizophrenia. Among patients using clozapine; the incidence of neutropenia is approximately $3 \%$ and the incidence of agranulocytosis is approximately $1 \%$. This side effect is diminishing after 18 weeks of drug initiation. Here, we present a case of clozapine-induced neutropenia in a schizophrenic patient seen after 7 years of clozapine use and its treatment with lithium supplementation.
\end{abstract}

Keywords: Clozapine, lithium, neutropenia.

\section{INTRODUCTION}

Clozapine is a second-generation antipsychotic drug proven to be effective in treatment-resistant schizophrenia. Among patients using clozapine, the incidence of neutropenia is approximately $3 \%$ and the incidence of agranulocytosis (neutrophils $<500 / \mathrm{mm}^{3}$ or white blood cells [WBC] $<1000 / \mathrm{mm}^{3}$ ) is approximately $1 \%$ (1). In a recent meta-analysis involving 108 studies, the incidence of clozapine-associated neutropenia was $3.8 \%$ and severe neutropenia was $0.9 \%$ (2). The period of greatest risk for both neutropenia and agranulocytosis is during the first 6-18 weeks of treatment (1). During the first 18 weeks of clozapine use, full blood count tests must be run weekly, later every month.

Clozapine therapy is recommended to be discontinued when WBC $<2000 / \mathrm{mm}^{3}$ or neutrophils $<1000 / \mathrm{mm}^{3}$. However, despite the development of neutropenia, it has been suggested that the use of clozapine may be continued with the addition of lithium or G-CSF in cases of resistant schizophrenia.
The rechallenge choice should be made taking into consideration the benefits and damages of the treatment $(3,4)$.

In this case report, clozapine-induced neutropenia in a schizophrenic patient after 7 years of clozapine use and its treatment with lithium supplementation will be presented.

\section{CASE}

A 45-year-old male patient with a 20-year schizophrenia diagnosis was admitted to hospital with irritability, aggression, disorganized speech, auditory and visual hallucinations. He had been using clozapine $600 \mathrm{mg} /$ day for 7 years and his general condition had deteriorated for the last 3 months. One month ago, clozapine treatment was discontinued because of decreasing trends of neutrophils (neutrophils: 1140/ $\mathrm{mm}^{3}$ ) and the patient was admitted to the clinic on haloperidol $20 \mathrm{mg}$ /day, quetiapine XR $300 \mathrm{mg}$ /day, and biperiden $4 \mathrm{mg} /$ day. Considering the extrapyramidal

How to cite this article: Tas Durmus P, Gorgulu Y, Sonmez MB, Kose Cinar R. Late-Onset Clozapıne-Induced Neutropenia Treated with Lithium. Dusunen Adam The Journal of Psychiatry and Neurological Sciences 2019;32:74-77.

Correspondence: Pelin Tas Durmus, Trakya University, Faculty of Medicine, Department of Psychiatry, Edirne, Turkey

Phone: +90-284-235-7641/1831 E-mail: t_pelin_t@hotmail.com

Received: April 24, 2018; Revised: May 22, 2018; Accepted: July 17, 2018 
side effects associated with the current treatment, olanzapine $30 \mathrm{mg} /$ day was started. There was no regression of the psychotic symptoms and catatonic features started to manifest in the patient (who did not benefit from antipsychotics other than clozapine). Given that the blood count values were found to be normal (WBC: 5010/. $\mathrm{mm}^{3}$ and neutrophils: $3030 / \mathrm{mm}^{3}$ ), clozapine was increased to $450 \mathrm{mg} /$ day.

On the $32^{\text {nd }}$ day of clozapine treatment, WBC count was found to be $8680 / \mathrm{mm}^{3}$, neutrophils $7080 / \mathrm{mm}^{3}$ and CRP (C-reactive protein) $20.3 \mathrm{mg} / \mathrm{dL}$. The patient was later diagnosed with pneumonia and was started on gemifloxacin $320 \mathrm{mg} /$ day. On the $4^{\text {th }}$ day of antibiotherapy, WBC, neutrophils, and CRP decreased to $2250 / \mathrm{mm}^{3}, 740 / \mathrm{mm}^{3}$ and $4.74 \mathrm{mg} / \mathrm{L}$, respectively. Blood count analysis on the same day revealed a leukocyte count of $1850 / \mathrm{mm}^{3}$ and a neutrophil count of $670 / \mathrm{mm}^{3}$. The patient was referred to hematology with an indication of G-CSF (Granulocyte Colonystimulating Factor) administration, but there was no indication as the patient had no fever. Because of neutropenia, clozapine treatment was discontinued, but subsequently, psychotic symptoms increased. As a result, the olanzapine dose was increased to $40 \mathrm{mg} /$ day, but there was no improvement in the psychotic symptoms. An increase in catatonia and disorganized speech and behavior were observed. The patient's leukocyte counts, specifically neutrophils, were seen to be normal. The patient was referred to hematology and was restarted on clozapine treatment because his health was deteriorating after the psychotic exacerbation; the condition was resistant to other antipsychotic treatments and the patient's next of kin did not consent to electroconvulsive therapy. The current treatment was strengthened with amisulpride $600 \mathrm{mg} /$ day. We followed the patient, but the blood counts continued to decrease (WBC: $4580 / \mathrm{mm}^{3}$ neutrophils: $2000 / \mathrm{mm}^{3}$ ). The patient was referred to hematology again to determine a possible risk of agranulocytosis. Immediate treatment was not recommended, but continuation of the existing treatment and G-CSF was suggested in case the neutrophil count went below $1000 / \mathrm{mm}^{3}$. With no indication of G-CSF treatment but a continuing decrease in neutrophils, we decided to add $900 \mathrm{mg} /$ day of lithium to the clozapine. In the following 3 days, an increase in leukocyte and neutrophil values (WBC: $6000 / \mathrm{mm}^{3}$ neutrophils: $3600 / \mathrm{mm}^{3}$ ) was observed. While the patient was on $900 \mathrm{mg}$ /day lithium, the blood count was monitored every day, and the clozapine dose was increased to $400 \mathrm{mg}$ /day while olanzapine was tapered off. The patient showed a regression of psychotic symptoms. He had no disorganized speech or behavior. He was discharged on clozapine $400 \mathrm{mg} /$ day, lithium $900 \mathrm{mg} /$ day, amisulpride $600 \mathrm{mg} /$ day, biperiden $2 \mathrm{mg} /$ day, and weekly blood count monitoring was recommended. On the day of discharge, WBC count was $6010 / \mathrm{mm}^{3}$, neutrophil count was $3290 / \mathrm{mm}^{3}$, and serum lithium level was $0.423 \mathrm{mmol} / \mathrm{L}$. The patient was seen 2.5 years later and no psychotic symptoms or disorganized speech or behavior were observed, with values of WBC: $8300 / \mathrm{mm}^{3}$, neutrophils: $5400 / \mathrm{mm}^{3}$, and serum lithium: $0.4 \mathrm{mmol} / \mathrm{L}$.

\section{DISCUSSION}

We have presented a case of clozapine-induced neutropenia. Interestingly, neutropenia emerged very late, in the $7^{\text {th }}$ year of the treatment. Clozapine was restarted after the psychiatric condition worsened as a result of the termination of clozapine treatment. During the second course of clozapine, neutropenia was treated with lithium. Within the first 6 months, agranulocytosis associated with the use of clozapine emerges in $90 \%$ of patients (5). Over time, the risk of developing agranulocytosis decreases (6). After 1 year of treatment with clozapine, the risk of developing neutropenia or agranulocytosis was found to be less than 1\% (7). There are other cases in the literature with clozapine-induced late-onset agranulocytosis/neutropenia (8-10). It is not recommended to start patients who previously experienced clozapine-induced neutropenia on clozapine treatment again because of a serious risk for developing neutropenia again, found to be $38 \%$ (6). Clozapine treatment is only recommended to be restarted in schizophrenic patients who are resistant to other antipsychotics in combination with lithium (1113) or G-CSF (14-16).

G-CSF is a cytokine that directly stimulates the proliferation of hematopoietic precursors and terminal granulocytic differentiation, with the most commonly reported rechallenge strategy being three times per week with 150 to $480 \mu \mathrm{g}$ of filgrastim per day. In a study analyzing 17 articles based on case reports of G-CSF rechallenge, there were no drug-specific side effects except for one reported case of euphoria (17). However, another study reported bone pain, rare instances of splenic rupture, allergic reactions exacerbation of autoimmune disorders, lung injury, and vascular events as potential side effects of G-CSF (18).

We chose augmentation with lithium for the recurrence of clozapine-induced neutropenia because G-CSF treatment was not recommended as the 
neutrophil counts were found to be low but not below $1000 / \mathrm{mm}^{3}$ and there was no fever. In the first 3 days of treatment with $900 \mathrm{mg}$ /day lithium, leukocyte and neutrophil counts were rising. The mechanism of lithium is not fully understood; however, a direct stimulation of the stem cells, GM-CSF, cytokine and demargination are believed to play a role (19).

Studies on the combination of clozapine and lithium are not sufficient. There are potential serious side effects like weight gain and metabolic abnormalities (11). An increased risk for epileptic seizures with the combination of lithium and clozapine should be monitored. The risk of developing neurotoxicity in patients treated with the combination of lithium and clozapine is approximately $20 \%$ (20). There is one case of a patient who benefited from clozapine rechallenge with lithium for 14 months, but eventually developed neurotoxicity. As a result, lithium was discontinued (21).

Although serum lithium levels do not appear to have a correlation with neutrophil levels (22), there are studies suggesting that the minimum lithium levels should be $0.4 \mathrm{mmol} / \mathrm{L}$ (23). The combination of clozapine and lithium is effective when administered within an optimal lithium dose range of $300-900 \mathrm{mg} /$ day with serum lithium levels between 0.4 and 0.9 $\mathrm{mmol} / \mathrm{L}(24,25)$. We also administered $900 \mathrm{mg}$ /day of lithium and kept the serum lithium level in our patient around $0.4 \mathrm{mmol} / \mathrm{L}$. More studies on the combination of clozapine with lithium or G-CSF are recommended.

We found this case to be worth presenting because it shows a patient whose schizophrenia is resistant to antipsychotics other than clozapine who developed recurrent clozapine-induced neutropenia and showed remission on hematologic and psychiatric parameters with lithium treatment.

\begin{tabular}{|c|c|c|}
\hline \multicolumn{2}{|c|}{ Contribution Categories } & \multirow{2}{*}{$\begin{array}{l}\text { Author Initials } \\
\text { P.T.D. }\end{array}$} \\
\hline \multirow{4}{*}{ Category 1} & Concept/Design & \\
\hline & Literature review & M.B.S., R.K.Ç. \\
\hline & Data analysis/Interpretation & P.T.D., Y.G. \\
\hline & Case follow-up (if applicable) & P.T.D., Y.G. \\
\hline \multirow{2}{*}{ Category 2} & Drafting manuscript & P.T.D., Y.G. \\
\hline & Critical revision of manuscript & P.T.D., Y.G. \\
\hline Category 3 & Final approval and accountability & P.T.D., Y.G., M.B.S., R.K.Ç. \\
\hline \multirow{2}{*}{ Other } & Technical or material support & P.T.D. \\
\hline & Supervision & Y.G. \\
\hline
\end{tabular}

Ethics Committee Approval: None declared.

Informed Consent: Written informed consent was obtained from the patient for the publication of the case report.

Peer-review: Externally peer-reviewed.
Conflict of Interest: All authours declares that there is no conflict of interest.

Financial Disclosure: None declared.

\section{REFERENCES}

1. Rajagopal S. Clozapine, agranulocytosis and benign ethnic neutropenia. Postgrad Med J 2005; 81:545-546.

2. Myles N, Myles H, Xia S, Large M, Kisely S, Galletly C, Bird $\mathrm{R}$, Siskind D. Meta-analysis examining the epidemiology of clozapine-associated neutropenia. Acta Psychiatr Scand 2018; 138:101-109.

3. Simon L, Cazard F. Clozapine rechallenge after neutropenia in resistant schizophrenia: a review. Encephale 2016; 42:346-353. (French)

4. Meyer N, Gee S, Whiskey E, Taylor D, Mijovic A, Gaughran F, Shergill S, MacCabe JH. Optimizing outcomes in clozapine rechallenge following neutropenia: a cohort analysis. J Clin Psychiatry 2015; 76:e1410-e1416.

5. Alvir JM, Lieberman JA, Safferman AZ, Schwimmer JL, Schaaf JA. Clozapine-induced agranulocytosis. Incidence and risk factors in the United States. N Engl J Med 1993; 329:162-167.

6. Dunk LR, Annan LJ, Andrews CD. Rechallenge with clozapine following leucopenia or neutropenia during previous therapy. $\mathrm{Br}$ J Psychiatry 2006; 188:255-263.

7. Ghaznavi S, Nakic M, Rao P, Hu J, Brewer JA, Hannestad J, Bhagwagar Z. Rechallenging with clozapine following neutropenia: treatment options for refractory schizophrenia. Am J Psychiatry 2008; 165:813-818.

8. Cohen D, Monden M. White blood cell monitoring during longterm clozapine treatment. Am J Psychiatry 2013; 170:366-369.

9. Patel NC, Dorson PG, Bettinger TL. Sudden late onset of clozapine-induced agranulocytosis. Ann Pharmacother 2002; 36:1012-1015.

10. Raja M, Azzoni A, Maisto G. Late onset neutropenia associated with clozapine. J Clin Psychopharmacol 2011; 31:780-781.

11. Brunoni AR, Kobuti Ferreira LR, Gallucci-Neto J, Elkis H, Velloso ED, Vinicius Zanetti M. Lithium as a treatment of clozapineinduced neutropenia: a case report. Prog Neuropsychopharmacol Biol Psychiatry 2008; 32:2006-2007.

12. Sporn A, Gogtay N, Ortiz-Aguayo R, Alfaro C, Tossell J, Lenane M, Gochman P, Rapoport JL. Clozapine-induced neutropenia in children: management with lithium carbonate. J Child Adolesc Psychopharmacol 2003; 13:401-404.

13. Suraweera C, Hanwella R, de Silva V. Use of lithium in clozapineinduced neutropenia: a case report. BMC Res Notes 2014; 7:635.

14. Hazewinkel AW, Bogers JP, Giltay EJ. Add-on filgrastim during clozapine rechallenge unsuccessful in preventing agranulocytosis. Gen Hosp Psychiatry 2013; 35:576e11-576e12.

15. Khan AA, Harvey J, Sengupta S. Continuing clozapine with granulocyte colony-stimulating factor in patients with neutropenia. Ther Adv Psychopharmacol 2013; 3:266-271. 
16. Lally J, Malik S, Whiskey E, Taylor DM, Gaughran FP, Krivoy A, Flanagan RJ, Mijovic A, MacCabe JH. Clozapine-associated agranulocytosis treatment with granulocyte colony-stimulating factor/granulocyte-macrophage colony stimulating factor: A systematic review. J Clin Psychopharmacol 2017; 37:441-446.

17. Myles N, Myles H, Clark SR, Bird R, Siskind D. Use of granulocytecolony stimulating factor to prevent recurrent clozapine-induced neutropenia on drug rechallenge: A systematic review of the literature and clinical recommendations. Aust N Z J Psychiatry 2017; 51:980-989.

18. Tigue CC, McKoy JM, Evens AM, Trifilio SM, Tallman MS, Bennett CL. Granulocyte-colony stimulating factor administration to healthy individuals and persons with chronic neutropenia or cancer: an overview of safety considerations from the Research on Adverse Drug Events and Reports project. Bone Marrow Transplant 2007; 40:185-192.

19. Paton C, Esop R. Managing clozapine-induced neutropenia with lithium. Psychiatric Bulletin 2005; 29:186-188.

20. Rosli ANM, Subbiah R, Maniam T. Clozapine re-challenge with lithium supplementation following clozapine-induced neutropenia. ASEAN Journal of Psychiatry 2014; 15:90-92.

21. Dumas R, Bardin P, Vedie C. Long-term treatment of clozapineinduced leukopenia with lithium: fast-onset agranulocytosis following lithium discontinuation. Prim Care Companion CNS Disord 2016; 18:1.

22. Lapierre G, Stewart RB. Lithium carbonate and leukocytosis. Am J Hosp Pharm 1980; 37:1525-1528.

23. Blier P, Slater S, Measham T, Koch M, Wiviott G. Lithium and clozapine-induced neutropenia/agranulocytosis. Int Clin Psychopharmacol 1998; 13:137-140.

24. Pinninti NR, Houdart MP, Strouse EM. Case report of longterm lithium for treatment and prevention of clozapineinduced neutropenia in an African American male. J Clin Psychopharmacol 2010; 30:219-221.

25. Aydin M, Ilhan BC, Calisir S, Yildirim S, Eren I. Continuing clozapine treatment with lithium in schizophrenic patients with neutropenia or leukopenia: brief review of literature with case reports. Ther Adv Psychopharmacol 2016; 6:33-38. 